\title{
Femoral arterial cannulation remains a safe and reliable option for aortic dissection repair
}

\author{
Anthony Lemaire, Joshua Chao, Lauren Salgueiro, Hirohisa Ikegami, Leonard Y. Lee \\ Rutgers Robert Wood Johnson Medical Center, New Brunswick, USA \\ Contributions: (I) Conception and design: A Lemaire; (II) Administrative support: None; (III) Provision of study materials or patients: None; (IV) \\ Collection and assembly of data: J Chao, L Salgueiro; (V) Data analysis and interpretation: H Ikegami, LY Lee; (VI) Manuscript writing: All authors; \\ (VII) Final approval of manuscript: All authors. \\ Correspondence to: Anthony Lemaire, MD. Associate Professor, Division of Cardiothoracic Surgery, Department of Surgery, Rutgers-Robert Wood \\ Johnson Medical School, 125 Paterson Street, New Brunswick, USA. Email: Anthony.lemaire@rwjms.rutgers.edu.
}

\begin{abstract}
Background: The optimal cannulation site for repair of type A aortic dissection remains controversial. The concern for Malperfusion syndrome has initiated a national trend away from femoral cannulation to axillary artery and direct ascending aortic cannulation. The purpose of this study was to report a single center experience with femoral artery cannulation for the repair of a type A dissection.

Methods: A retrospective study was performed on 52 patients who underwent surgical repair for a type A dissection between January $1^{\text {st }}, 2012$ and June $30^{\text {th }}, 2019$ at a single institution. Of the 52 patients analyzed, $35(67.3 \%)$ underwent femoral artery, 11 (21.2\%) direct ascending aortic, and $6(11 \%)$ axillary artery cannulation for arterial access. Deep hypothermic circulatory arrest was used in all the patients. Rates of postoperative complication and mortality were reported.

Results: The mortality and bleeding rates for all the patients undergoing repair of the type A dissection repairs were $27 \%(14 / 52)$ and 19\% (10/52), respectively. Cardiopulmonary bypass was established in $100 \%$ of the patients that had femoral arterial cannulation. There were no complications specifically related to femoral arterial cannulation nor the axillary or direct aortic approach. Specifically, there was no episodes of malperfusion syndrome, bleeding, or injury with femoral artery cannulation. Bleeding rates were higher in cases that proceeded with a femoral (13\%) versus alternate $(6 \%)$ approach however; neither of the bleeding was related to the cannulation site. None of the mortalities identified were directly attributable to the cannulation approach in each case.
\end{abstract}

Conclusions: Despite the recent shift away from femoral cannulation, the results of the study show that femoral artery cannulation is safe and produces excellent results for establishing cardiopulmonary bypass.

The concerns for malperfusion syndrome related to femoral cannulation were not seen.

Keywords: Aortic dissection; femoral artery; malperfusion

Submitted Jul 28, 2020. Accepted for publication Dec 17, 2020.

doi: $10.21037 /$ jtd-20-2549

View this article at: http://dx.doi.org/10.21037/jtd-20-2549

\section{Introduction}

Acute dissection of the ascending aorta is a lethal disease that requires prompt diagnosis and surgical intervention (1). It is the most common and disastrous event to affect the aorta. The dissection of the thoracic aorta occurs nearly 3 times as frequently as rupture of the abdominal aortic aneurysms in the United States (2). The annual incidences for acute aortic dissection are by comparison low: 440 per 100,000 for acute coronary syndrome, 69 per 100,000 for pulmonary embolism, and 3 to 4 per 100,000 for acute aortic dissection $(3,4)$. The location of the aortic tear determines the surgical approach and the timing of intervention. One of the critical aspects of type A dissections is establishing cardiopulmonary 
bypass for replacement of the ascending aorta. Arterial cannulation is essential and the anatomical location has important implications. Femoral arterial cannulation initially was the standard for arterial cannulation and had been established for cardiopulmonary bypass since the 1950's (5). The risks associated with its use however includes distal re-entry, distal embolization because of retrograde perfusion to the brain, and malperfusion syndrome. One of the most feared complications of acute aortic dissection is end-organ malperfusion and there is an incidence of it as high as $28 \%$ to $31 \%(6,7)$. Malperfusion is defined as diminished blood flow to the arterial bed of a vital organ. A malperfusion syndrome is when this diminished flow results in ischemia and subsequent impairment of function (malperfusion syndrome). This can present physically as abdominal pain due to visceral ischemia or physiologically (neurologic changes related to stroke) (8).

Over the last 2 decades, there was a shift towards alternative access sites for arterial cannulation for repair of type A aortic dissections. Initially the axillary artery became the primary alternative cannulation site. The Cleveland clinic was instrumental in its use for cannulation with their original publication in 1995 (9). The benefit of the alternative access site is that it provides antegrade cerebral perfusion to reduce the risk of stroke and embolization. The common issue with both peripheral arterial cannulation sites are that they both require an additional incision that maybe time-consuming depending on the patient's anatomy. Of late, central aortic cannulation has become more popular either with direct cannulation of the ascending aorta or through the innominate artery. The advantages of the more direct approach include the single incision for repairing the dissection, antegrade cerebral perfusion, and prevention of distal embolization.

The concern for malperfusion syndrome is one of the key factors that has initiated a national trend away from femoral cannulation to axillary artery and direct ascending aortic cannulation. The purpose of this study was to report a single center experience with femoral artery cannulation for the repair of a type A dissection. Regardless of the alternate cannulation sites, an analysis of the traditional femoral arterial cannulation site is important to assess how it compares to the different options. We present the following article in accordance with the STROBE reporting checklist (available at http://dx.doi.org/10.21037/jtd-20-2549).

\section{Methods}

A retrospective study was performed on 52 consecutive patients who underwent surgical repair for a type A aortic dissection between January $1^{\text {st }}, 2012$ and June $30^{\text {th }}, 2019$ at a single institution. An analysis from the International Registry of Acute Aortic Dissections (IRAD) reported a mean age at presentation of 63 years and a male predominance of $61 \%$, yielding an incidence of 16 per 100,000 in men $(10,11)$. Similar to the IRAD data, the majority of the patients in the study were male $(\mathrm{N}=34,65 \%)$ and the mean age was $66 \pm 12$ (Table 1). The cardiothoracic surgeon's decision on the best arterial cannulation site is critical. Of the 52 patients analyzed, $35(67.3 \%)$ underwent femoral artery, $11(21.2 \%)$ direct ascending aortic, and $6(11 \%)$ axillary artery cannulation for arterial access. The entire patient group had central cannulation of the right atrium for venous access. All of the procedures were performed in the operative theater at a single academic institution. Deep hypothermic circulatory arrest and unilateral antegrade cerebral perfusion were used in all the patients. The rates of postoperative complication, mortality, and demographic data were reported. This study was conducted in accordance with the Declaration of Helsinki (as revised in 2013). The study was approved by the institutional review board and ethics committee (No: 2020000011). Individual consent for this retrospective analysis was waived.

\section{Statistical analysis}

Continuous variables were expressed as median with an interquartile range (IQR), and categorical variables were expressed as count (percentage). We utilized the MannWhitney $\mathrm{U}$ test for continuous variables and Chi-Square for categorical variables. The Kaplan-Meier survival analysis was used to estimate survival. $\mathrm{P}$ values less than 0.05 were considered statistically significant.

\section{Results}

The critical aspects of repair of ascending aortic dissection involves first starting cardiopulmonary bypass to prevent further aortic rupture. Successful arterial and venous cannulation are crucial towards the re-establishment of arterial flow through the true lumen of the aorta for repair. In this study, cardiopulmonary bypass was established in $100 \%$ of the patients that had femoral arterial cannulation. The femoral artery was accessed by cut down to the artery followed by cannulation using Seldinger technique under transesophageal echocardiogram (TEE) guidance. A wire in 
Table 1 Baseline demographic and clinical characteristics

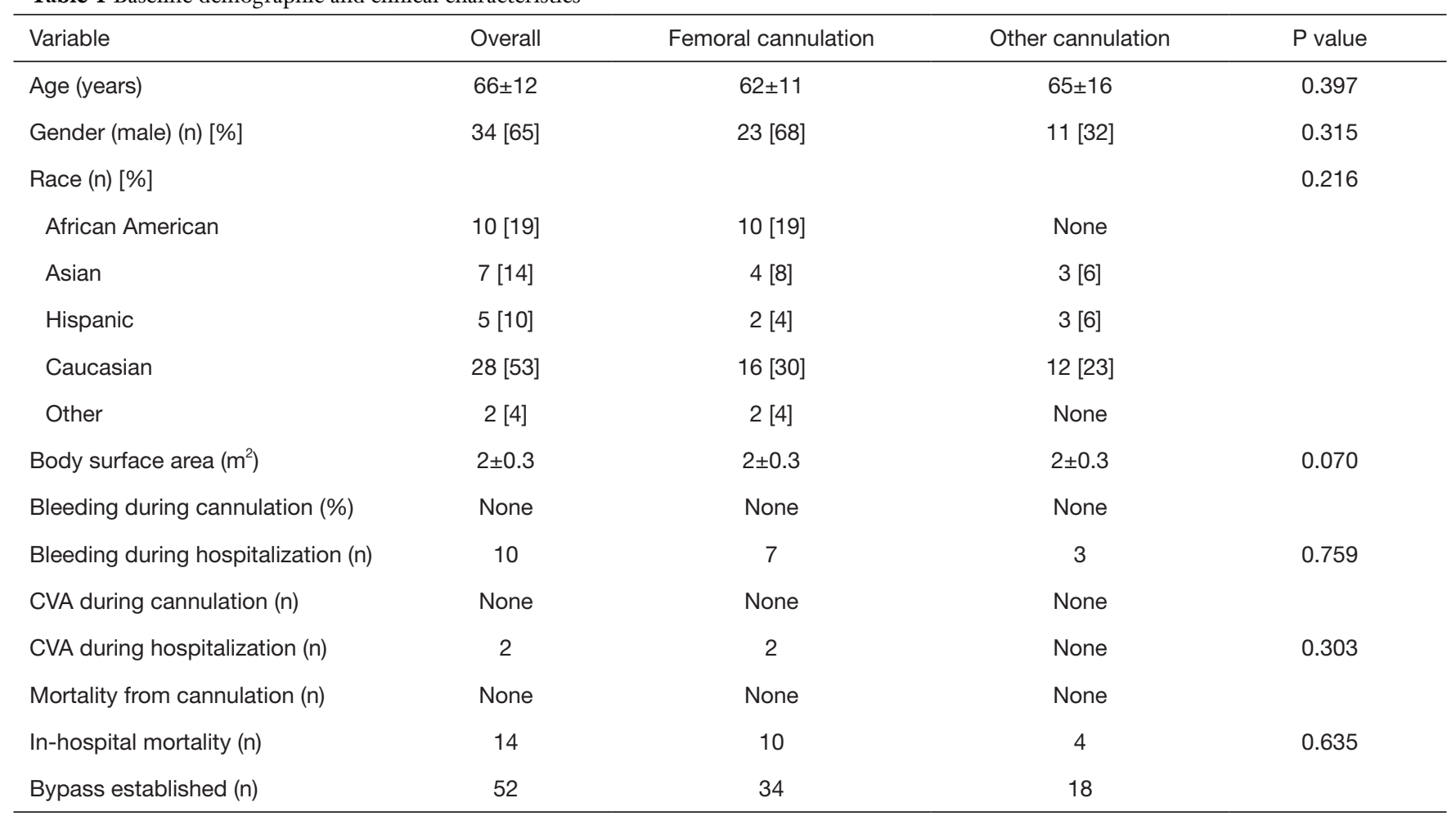

the true lumen of the aorta was confirmed by TEE prior to placement of the arterial cannula.

There were no complications specifically related to femoral arterial cannulation nor the axillary or direct aortic approach. The cannulation of the femoral artery had no episodes of malperfusion syndrome, bleeding, or injury. Similarly, there no issues related to directly cannulating the axillary artery, or central ascending aorta. The bleeding rates for the patients were higher in cases that proceeded with a femoral $(13 \%)$ versus alternate $(6 \%)$ approach however, neither of the bleeding was related to the cannulation site (Figure 1). The mortality and bleeding rates for all the patients undergoing repair of the type A dissection repairs were $27 \%(14 / 52)$ and 19\% (10/52), respectively. These findings reinforce the severity of the disease process of aortic dissections.

\section{Discussion}

Despite the shift away from femoral cannulation, the results of the study show that femoral artery cannulation is safe and produces excellent results for establishing cardiopulmonary bypass. The concerns for malperfusion syndrome related to femoral cannulation did not occur. Specifically, there were no cases where there was evidence of dynamic flow obstruction after cannulation of the femoral artery. It is critical that the cardiac surgery team identify if a problem occurs with perfusion and if that occurs an alternative site has to be chosen. There were no direct injuries to the femoral artery or any problem with cannulating the artery that necessitated moving to another access site. Interestingly, one of the additional benefits of the femoral artery is that if there was an issue with one of the femoral arteries, then the contralateral artery could be used. Although, the same applies to the axillary artery, an injury or complication with central aortic cannulation is more detrimental. As cardiothoracic surgeons become more experienced with operating on patients with type A aortic dissections, the treatment strategy has evolved. Arterial cannulation through the femoral arteries had been the primary artery for cannulation. The findings of the study demonstrate that the femoral artery can still be used as an arterial cannulation site.

The primary benefits to the femoral artery are that it is easily accessible, and no graft anastomosis is required which allows for prompt cannulation. An additional advantage is 


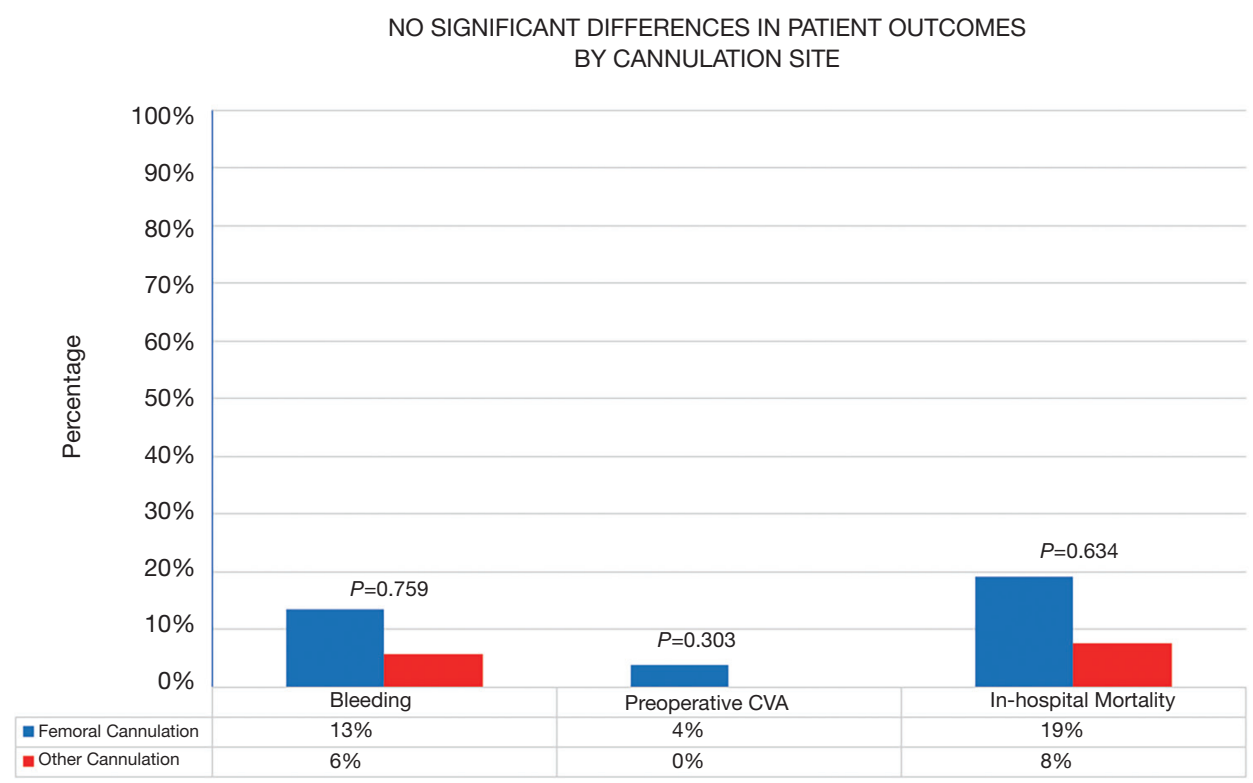

Figure 1 Postoperative complication rates of femoral cannulation approach versus either axillary or ascending aorta cannulation approaches.

that is allows for initiating cardiopulmonary bypass prior to making the sternotomy or even cooling the patient for circulatory arrest. Furthermore, the presence of bilateral femoral arteries allows for 2 potential arteries to cannulate. Often if there is an issue with 1 femoral artery, either calcification or just difficult to access then the contralateral femoral artery can be cannulated. Moreover, most clinicians feel comfortable with accessing the femoral arteries with the use of ultrasound. This is in contrast to the axillary artery which are not typically accessed with ultrasound. The inherent disadvantages however, include the risk of Malperfusion, retrograde flow to the brain, and potential injury to the artery distally leading to vascular compromise to the lower extremity. Another potential problem is embolization of plaque to the brain. The shift away from the femoral artery was to identify another artery that can provide antegrade flow to all the major organs and prevent malperfusion, as well as decrease risk of embolization to the brain. As previously mentioned, the alternative options include the axillary artery, innominate artery, and direct ascending aorta.

The axillary artery is an alternative peripheral artery similar to the femoral artery but it requires experience with the axillary artery anatomy. Knowledge of the axillary vein and brachial plexus are important to cannulate the axillary artery and prevent injury to the surrounding structures. Once identified the axillary artery generally requires a graft sutured to it for arterial cannulation. The artery can be cannulated without the use of a graft, however that can often lead to injury as the axillary artery is often small. The key advantages of the axillary artery are that it provides antegrade perfusion to the brain and other major organs, and allows for unilateral cerebral perfusion. An additional benefit is that there is less risk of having a dissected axillary artery. In our experience we most often identified the aortic dissection extending to one of the femoral arteries versus the axillary arteries. Although the axillary artery became more frequently used compared to the femoral artery, central arterial cannulation has gained popularity. The central approach can be either from the innominate artery or directly through the ascending aorta. Both options provide antegrade perfusion, a single surgical approach, and avoid the use of a graft.

The highest mortality from aortic dissection occurs in the first 48 hours after symptom onset; therefore, immediate diagnosis and treatment is lifesaving. Operative 30-day mortality for ascending aortic dissections at experienced centers (involving selective cerebral vessel perfusion) is between $10 \%$ and $35 \%(12,13)$. The wide range in mortality demonstrates that multiple factors can affect outcome. One crucial aspect is successfully establishing cardiopulmonary bypass with proper arterial and venous cannulation. Unfortunately, at this time, the optimal cannulation site for repair of Type A Aortic dissection remains controversial 
$(14,15)$. A consensus concerning the most optimal cannulation strategy for patients with this emergency condition is still lacking $(16,17)$. The ideal cannulation strategy for aortic dissection is quick to establish, minimizes any organ Malperfusion, prevents progression of the dissection flap, and allows optimal brain protection (18).

\section{Limitations}

Despite the findings of the study there are limitations that require consideration when reviewing the data. First, as a retrospective study there are inherent potential limitations such as bias that could occur. In order to prevent this, all data was analyzed by 1 cardiothoracic surgeon but also by an independent non-cardiothoracic surgeon to confirm the accuracy of the data. Secondly, although the sample size is adequate a larger sample size of over a 100 patients would be ideal. Aortic dissections are rare surgical emergencies and therefore obtaining a larger sample size is challenging. Although there are potential constraints, the findings of the study are valid and should be able to educate cardiothoracic surgeons.

\section{Conclusions}

Taken together, all of the alternative approaches provide some advantages and disadvantages. The critical concern with femoral arterial cannulation is Malperfusion and that was not found. The data of the study shows that femoral arterial cannulation remains a safe and reliable option that all cardiothoracic surgeons should be able to perform.

\section{Acknowledgments}

Funding: None.

\section{Footnote}

Reporting Checklist: The authors have completed the STROBE reporting checklist. Available at http://dx.doi. org/10.21037/jtd-20-2549

Data Sharing Statement: Available at http://dx.doi. org/10.21037/jtd-20-2549

Conflicts of Interest: All authors have completed the ICMJE uniform disclosure form (available at http://dx.doi. org/10.21037/jtd-20-2549). The authors have no conflicts of interest to declare.

Ethical Statement: The authors are accountable for all aspects of the work in ensuring that questions related to the accuracy or integrity of any part of the work are appropriately investigated and resolved. This study was conducted in accordance with the Declaration of Helsinki (as revised in 2013). The study was approved by the institutional review board and ethics committee (No: 2020000011). Individual consent for this retrospective analysis was waived.

Open Access Statement: This is an Open Access article distributed in accordance with the Creative Commons Attribution-NonCommercial-NoDerivs 4.0 International License (CC BY-NC-ND 4.0), which permits the noncommercial replication and distribution of the article with the strict proviso that no changes or edits are made and the original work is properly cited (including links to both the formal publication through the relevant DOI and the license). See: https://creativecommons.org/licenses/by-nc-nd/4.0/.

\section{References}

1. Mussa FF, Horton JD, Moridzadeh R, et al. Acute Aortic Dissection and Intramural Hematoma: A Systematic Review. JAMA 2016;316:754-63.

2. Coady MA, Rizzo JA, Goldstein LJ, et al. Natural history, pathogenesis, and etiology of thoracic aortic aneurysms and dissections. Cardiol Clin 1999;17:615-35; vii.

3. Hagan PG, Nienaber CA, Isselbacher EM, et al. The International Registry of Acute Aortic Dissection (IRAD): new insights into an old disease. JAMA 2000;283:897-903.

4. Abcarian PW, Sweet JD, Watabe JT, et al. Role of a quantitative $\mathrm{D}$-dimer assay in determining the need for CT angiography of acute pulmonary embolism. AJR Am J Roentgenol 2004;182:1377-81.

5. Lillehei CW, Cardozo RH. Use of median sternotomy with femoral artery cannulation in open cardiac surgery. Surg Gynecol Obstet 1959;108:706-14.

6. Fann JI, Sarris GE, Mitchell RS, et al. Treatment of patients with aortic dissection presenting with peripheral vascular complications. Ann Surg 1990;212:705-13.

7. Lauterbach SR, Cambria RP, Brewster DC, et al. Contemporary management of aortic branch compromise resulting from acute aortic dissection. J Vasc Surg 2001;33:1185-92.

8. Kamman AV, Yang B, Kim KM, et al. Visceral 
Malperfusion in Aortic Dissection: The Michigan

Experience. Semin Thorac Cardiovasc Surg 2017; 29:173-8.

9. Sabik JF, Lytle BW, McCarthy PM, et al. Axillary artery: an alternative site of arterial cannulation for patients with extensive aortic and peripheral vascular disease. J Thorac Cardiovasc Surg 1995;109:885-90; discussion 890-1.

10. Manfredini R, Boari B, Gallerani M, et al. Chronobiology of rupture and dissection of aortic aneurysms. J Vasc Surg 2004;40:382-8.

11. Trimarchi S, Nienaber CA, Rampoldi V, et al. Role and results of surgery in acute type $B$ aortic dissection: insights from the International Registry of Acute Aortic Dissection (IRAD). Circulation 2006;114:I357-64.

12. Tsai TT, Evangelista A, Nienaber CA, et al. Longterm survival in patients presenting with type A acute aortic dissection: insights from the International Registry of Acute Aortic Dissection (IRAD). Circulation 2006;114:1350-6.

13. Svensson LG, Kouchoukos NT, Miller DC, et al. Expert consensus document on the treatment of descending

Cite this article as: Lemaire A, Chao J, Salgueiro L, Ikegami H, Lee LY. Femoral arterial cannulation remains a safe and reliable option for aortic dissection repair. J Thorac Dis 2021;13(2):10051010. doi: $10.21037 /$ jtd-20-2549 thoracic aortic disease using endovascular stent-grafts. Ann Thorac Surg 2008;85:S1-41.

14. Klotz S, Heuermann K, Hanke T, et al. Outcome with peripheral versus central cannulation in acute Type A dissection dagger. Interact Cardiovasc Thorac Surg 2015;20:749-53; discussion 754.

15. Etz CD, Plestis KA, Kari FA, et al. Axillary cannulation significantly improves survival and neurologic outcome after atherosclerotic aneurysm repair of the aortic root and ascending aorta. Ann Thorac Surg 2008;86:441-6; discussion 446-7.

16. Kamiya H, Kallenbach K, Halmer D, et al. Comparison of ascending aorta versus femoral artery cannulation for acute aortic dissection type A. Circulation 2009;120:S282-6.

17. Reece TB, Tribble CG, Smith RL, et al. Central cannulation is safe in acute aortic dissection repair. J Thorac Cardiovasc Surg 2007;133:428-34.

18. Abe T, Usui A. The cannulation strategy in surgery for acute type A dissection. Gen Thorac Cardiovasc Surg 2017;65:1-9. 